\title{
ENERGY UTILIZABILITY CONCEPT AS A RETROFITTING SOLUTION SELECTION CRITERION FOR BUILDINGS
}

\author{
Junjing YANG ${ }^{\mathrm{a}}$, Adrian $\mathrm{CHONG}^{\mathrm{a}}{ }^{\mathrm{b}}$, Mat SANTAMOURIS ${ }^{\mathrm{c}}$, Denia KOLOKOTSA ${ }^{\mathrm{d}}$, \\ Siew Eang LEE ${ }^{\mathrm{a}}$, Kwok Wai THAM ${ }^{\mathrm{a}}$, Chandra SEKHAR ${ }^{\mathrm{a}}$, David Kok Wai CHEONGa \\ ${ }^{a}$ Department of Building, School of Design and Environment, National University of Singapore, \\ 4 Architecture Drive, 117566, Singapore \\ ${ }^{b}$ School of Architecture, Carnegie Mellon University, 5000 Forbes Ave, Pittsburgh, PA 15213, USA \\ ${ }^{c}$ Faculty of the Built Environment, University of New South Wales, Red Centre Building, \\ University Mall, Kensington NSW 2033, Australia \\ ${ }^{d}$ School of Environmental Engineering, Technical University of Crete, Chania 731 00, Greece
}

Received 26 Feb 2017; accepted 24 Apr 2017

\begin{abstract}
Retrofitting is widely explored as one of the energy conserving opportunities for existing buildings, in which both passive and active solutions are carefully evaluated. However, when different retrofitting solutions are combined and applied to a building, the total energy savings potential, which is less than the sum of the savings from applying the various individual retrofitting solutions, is considerably reduced and the synergies among the various technologies need to be understood and evaluated. In this study, the concept of utilizability is employed for the analysis of multiple energy retrofitting solutions in buildings and is defined as the ratio of energy savings derived from applying combined solutions to a building over the sum of individual energy savings from applying individual solutions. It is aimed at providing a better understanding of the combined retrofitting solutions. The sensitivity analysis on the utilizability value further provides a selection criterion for retrofitting solution selection.
\end{abstract}

Keywords: energy savings, energy plus simulation, retrofitting, utilizability, energy conserving opportunities, sensitivity analysis.

\section{Introduction}

Building sector is responsible for about $40 \%$ of the total energy consumption and the global demand is expected to grow in the next few decades (BPIE 2015). Between the year of 2010 and 2050, energy demand for heating and cooling over the world is expected to increase by $79 \%$ in residential buildings and $84 \%$ in commercial buildings (BPIE 2015).

Retrofitting has been widely studied to improve building energy efficiency and reduce the energy demand. Maintenance, new technologies and occupancy variations need to be continually taken into account through the upgrading of existing buildings. It not only helps to reduce the energy consumption, it is also an optimal solution for provide people a better community and indoor environment. Hence, different aspects including both the technology and occupancy demand control strategies have been investigated in detail, such as passive solutions: insulation materials (Aktacir et al. 2010); phase change materials (Pasupathy et al. 2008; Kuznik et al. 2011); interventions (de Santoli et al. 2016); green roof and green facades (Jim 2014); glazing (Özkan, Onan 2011); facade design (Sozer 2010); and cool roof (Akbari et al. 2006), etc. The main purpose of these passive solutions is to make utilization of passive environmental solutions to saving energy possible (Güçyeter, Günaydın 2012; Wong, Li 2007; Chua et al. 2013). Other than these, active solutions on the system side such as smart windows (Sabry et al. 2014), heat pumps (Bianco et al. 2017), and chilled beams (Nelson et al. 2016). Occupancy demand driven controls, such as $\mathrm{CO} 2$ based demand control ventilation (Yang et al. 2016a), occupancy state transitions based set point optimization (Yang, Becerik-Gerber 2017), occupancy diversity based HVAC system energy efficiency (Yang et al. 2016b) have been investigated and implemented to save energy consumption in buildings. As reported in Todorovic and Ecim (2010), there is a strong interest and demand for feasible methods where energy savings can be reached by combining those passive strategies with active energy saving systems. It is, therefore, necessary to exploit the combination potential of available technologies and systems in buildings.

Corresponding author: Junjing Yang

E-mail: bdgyj@nus.edu.sg 
Previous studies, which integrate both passive and active designs into a building retrofit intervention to minimize the energy demand and maximize the energy efficiency, have demonstrated that more than $50 \%$ reduction of the total cooling and heating load can be achieved (Nazi et al. 2015; Sekhar 2007; Pisello et al. 2015). However, thermodynamic constraints and the building physics would affect the savings from the combined solutions when compared with the individual ones.

The purpose of this study is to develop a methodology for the evaluation of combined retrofitting solutions, in order to be able to assess the impact of overlapping effects or synergistic benefits of different technologies focused on the maximum energy saving potential in comparison to the individual cases.

Considering that a building is complex in terms of its thermodynamics within which there is constantly energy exchange among different zones, systems and even with the outside environment, it would be challenging to take into account all the parameters to develop a theoretical rigour to predict the energy consumption of a building. Hence, EnergyPlus simulation tool is used to evaluate the building performance and the overlapping and synergistic effects when multiple retrofitting scenarios are applied.

Although the utilizability concept is not new, its expression and application in the field of building retrofitting solutions is not defined and studied. The aim of this paper is to develop such an expression for utilizability and explore its application for selecting the most appropriate retrofitting scenarios that would maximize the coverage of heating and cooling demand of existing buildings in a synergistic manner, and thereby, lead to minimising the wastage of energy saving potential of individual scenarios and maximising the cumulative or overall energy saving potential. In this context, the term utilizability is introduced and explained in Section 1. In Section 2, the methodology followed is explained while Section 3 includes the retrofitting solutions' results.

\section{Definition of utilizability}

As shown in Figure 1, the energy savings from the combination of two retrofitting solutions could be smaller than the sum of the energy savings applied to the same building because of the overlapping energy saving effect, shown as the shaded area. The total amount of energy savings would vary with the change of the physical parameters. Figure 2 shows the cooling load savings from two different retrofitting scenarios over one day. Retrofitting scenario 1 shows the replacement of the current clear glass window with a double glazed window while retrofitting scenario 2 is to add wall insulation. While the two scenarios show different patterns and load saving profiles over the day, the contribution may cover the same load profile and this leads to the utilizability concept.

Maximising the utilization of each retrofitting solution, energy saving potential, while also achieving the maximum saving amount, is indeed a tremendous chal-

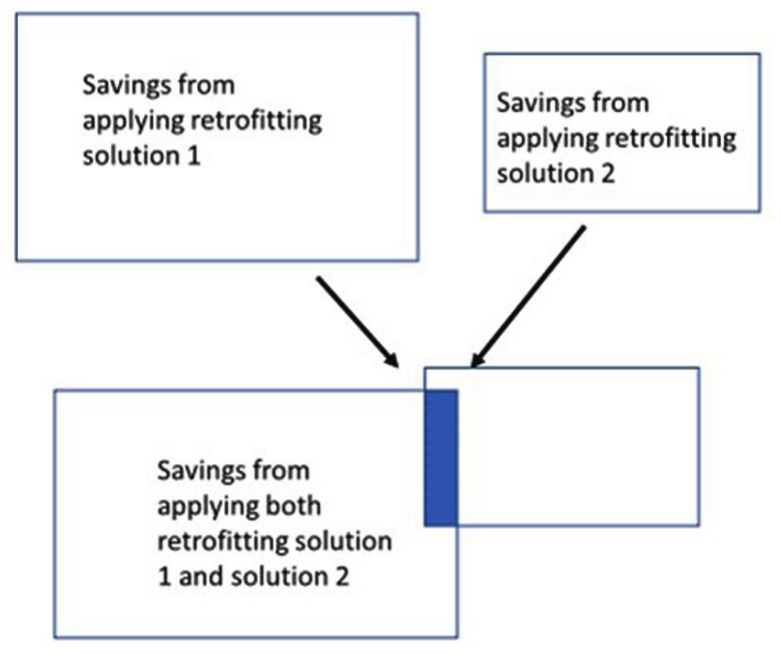

Fig. 1. Background of utilizability

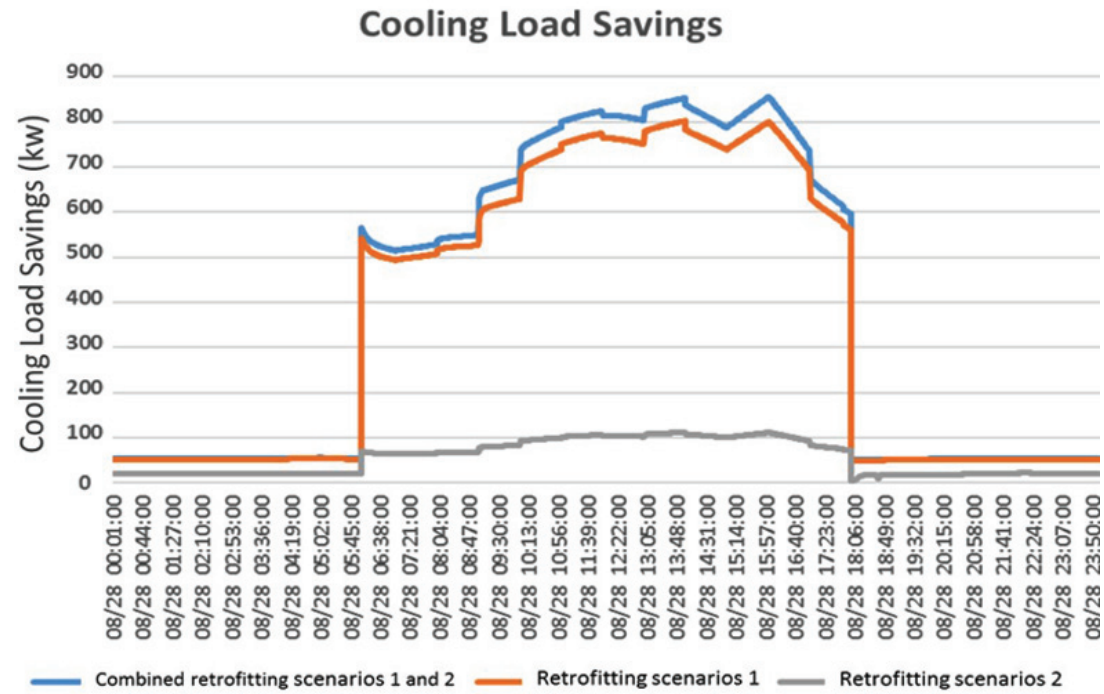

Fig. 2. Cooling load savings profile from two different retrofitting scenarios over one day 
lenge. There is a knowledge gap in this understanding when one attempts at choosing and applying more than one solution. In order to achieve energy efficiency with a more dynamic and comprehensive understanding, especially with the increasing focus on the utilization of different solutions when combined, this study, will explore further on the sensitivity analysis of building physical parameters on the utilizability of retrofitting solution combination.

The term utilizability is defined as:

$$
U F=\frac{E\left(r s_{1}, r s_{2}, \ldots . r s_{n}\right)}{\sum_{i}^{n} E\left(r s_{i}\right)},
$$

where: $E\left(r s_{1}, r s_{2}, \ldots . r s_{n}\right)$ - the energy savings of the combined retrofitting scenarios $r s_{1}$ to $r s_{n} ; \sum_{i}^{n} E\left(r s_{i}\right)$ - the sum of the energy savings for each retrofitting scenario when applied individualy.

The $U F$ will be less than 1 with the increase of $i$ (number of scenarios to be combined) if overlapping of retrofitting scenarios exist. It will be greater than 1 if synergistic effects exist among different retrofitting scenarios applied.

\section{Methodology}

\subsection{Case study building}

In this study, a campus building of the National University of Singapore is used (see Fig. 3). It has typical campus building functions consisting of offices, lecture rooms, studios, and research student rooms.

Floor-level air handling units (AHUs) based on a variable air volume (VAV) system design is the air conditioning system concept used and are served by a centralized chilled water system. The building has a typical reinforced concrete construction with more than 40 years age. The facade and the building system were renovated once 15 years ago and now have large retrofitting potential.

The building details are described in Table 1. The available building energy consumption data for this building consists of 2 parts: Plug load (Including the lighting

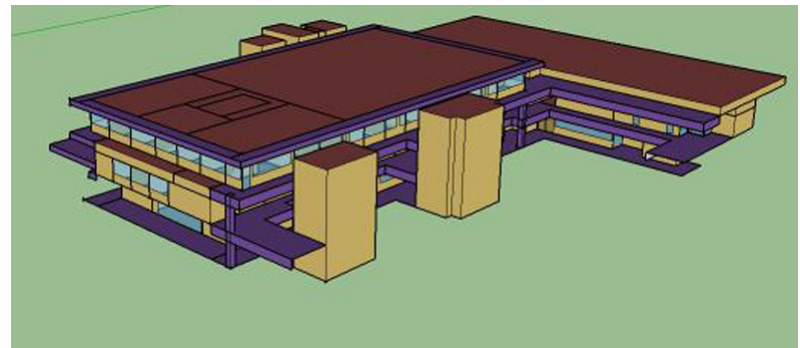

Fig. 3. Case study building

and equipment) and HVAC load. Energy data for the two parts are obtained for one year, i.e. 2013. Both of them are obtained through the University facility management office which records energy data of all campus buildings at every thirty minute interval. The data is available daily for 365 days but only weekday data are used in this study. Because of the tropical location, heating is not considered in this study.

\subsection{Analysis of retrofitting scenarios}

A previous study (Yang et al. 2016c) has observed the biggest characteristics and criticism of conventional HVAC systems in the buildings studied, which also demonstrated that the designs of plant and air-side strategies are less optimal for the building function. In order to have a relatively holistic selection of numerous retrofitting solutions, 5 solutions have been selected from operational related strategies and 5 from practical passive strategies in this study as shown in Table 2.

The above ten energy retrofitting solutions are the most common retrofitting solutions, especially in the tropics. The selection is based on the evaluations of previous 34 individual retrofitting scenarios for two different occupancy level buildings, to achieve high energy saving potential (Yang et al. 2016a).

The first five measures $\left(r s_{1}-r s_{5}\right)$ are able to have an improvement on the building envelope or facade. $r s_{1}$ and $r s_{2}$ consider the window optimization options. In $r s_{1}$, where replacement of the windows takes place, a U-value of $2.3 \mathrm{~W} / \mathrm{m}^{2} \mathrm{~K}$ is assumed for the new double glazed

Table 1. Building characteristics

\begin{tabular}{ll}
\hline & \multicolumn{1}{c}{ Building A } \\
\hline Age & 42 \\
Gross floor area & $5305 \mathrm{~m}^{2}$ \\
Chiller Plant Efficiency & $1.1 \mathrm{~kW} /$ ton \\
Roof & Metal roof \\
Glass door and window & $6 \mathrm{~mm}$ clear glass \\
Interior wall & $25 \mathrm{~mm}$ Gypsum board + Wall Insulation $+25 \mathrm{~mm}$ Gypsum board \\
Floor & $100 \mathrm{~mm}$ lightweight concrete +150 mm concrete \\
External wall & $50 \mathrm{~mm}$ Gypsum + concrete $+25 \mathrm{~mm}$ gypsum board \\
False ceiling & Acoustic tile \\
Chilled water supply temperature & $6.7^{\circ} \mathrm{C}$ \\
\hline
\end{tabular}


Table 2. Selected retrofitting scenarios and detail parameters in the various retrofitting solutions

\begin{tabular}{|c|c|c|c|}
\hline & $\begin{array}{l}\text { Retrofitting } \\
\text { Scenarios }\end{array}$ & Description & Detailed parameters \\
\hline \multirow{5}{*}{$\begin{array}{l}\text { Passive } \\
\text { solutions }\end{array}$} & $r s_{1}$ & $\begin{array}{l}\text { Replace Normal } 6 \mathrm{~mm} \text { clear glass } \\
\text { to double glazed low E glass }\end{array}$ & $\begin{array}{l}\text { Double glazed low E glass property: } \\
\left.\mathrm{U} \text {-value }=2.3 \mathrm{~W} / \mathrm{m}^{2} \mathrm{~K} \text { (Original value: } 4.8 \mathrm{~W} / \mathrm{m}^{2} \mathrm{~K}\right)\end{array}$ \\
\hline & $r s_{2}$ & $\begin{array}{l}\text { Add solar control film to the } \\
\text { existing normal } 6 \mathrm{~mm} \text { clear glass }\end{array}$ & $\begin{array}{l}\text { Solar control film property } \\
\mathrm{U}=3.5 \mathrm{~W} / \mathrm{m}^{2} \mathrm{~K} \text { (Original value: } 4.8 \mathrm{~W} / \mathrm{m}^{2} \mathrm{~K} \text { ) }\end{array}$ \\
\hline & $r s_{3}$ & $\begin{array}{l}\text { Add high performance insulation } \\
\text { layer to external wall }\end{array}$ & $\begin{array}{l}\text { External Wall Insulation layer Property: } \\
\text { Thickness: } 0.0337 \mathrm{~m} \\
\text { Conductivity: } 0.0432 \mathrm{~W} / \mathrm{mK} \\
\text { Density: } 91 \mathrm{~kg} / \mathrm{m}^{3} \\
\text { Specific heat: } 837 \mathrm{~J} / \mathrm{kg} . \mathrm{K}\end{array}$ \\
\hline & $r s_{4}$ & Add roof insulation & $\begin{array}{l}\text { Roof Insulation layer Property Thickness: } \\
0.1693 \mathrm{~m} \\
\text { Conductivity: } 0.049 \mathrm{~W} / \mathrm{mK} \\
\text { Density: } 265 \mathrm{~kg} / \mathrm{m}^{3} \\
\text { Specific heat: } 836.8 \mathrm{~J} / \mathrm{kg} . \mathrm{K} \\
\end{array}$ \\
\hline & $r s_{5}$ & Use cool roof & $\begin{array}{l}\text { Cool Roof Property: } \\
\text { Thickness: } 0.1693 \mathrm{~m} \\
\text { Albedo: } 0.9\end{array}$ \\
\hline \multirow{5}{*}{$\begin{array}{l}\text { Active } \\
\text { Solutions }\end{array}$} & $r s_{6}$ & $\begin{array}{l}\text { Active Chilled Beam with DOAS } \\
\text { system }\end{array}$ & $\begin{array}{l}\text { Chilled water to Chilled Beam cooling coil: } 17 \text { supply, } \\
19 \text { return } \\
\text { Chilled water to outdoor air cooling coil: } 6.7^{\circ} \mathrm{C}\end{array}$ \\
\hline & $r s_{7}$ & Reduce infiltration rate by half & $\begin{array}{l}\text { The original infiltration rate is obtained from an earlier audit } \\
\text { report: } \\
\text { Studio: } 1.3 \mathrm{ACH} \\
\text { Offices: } 2 \mathrm{ACH} \\
\text { Labs: } 2 \mathrm{ACH} \\
\text { CIRCULATION SPACES: } 2.1 \mathrm{ACH} \\
\text { Research student room: } 3 \mathrm{ACH} \\
\text { The new infiltration rate is half of the original one for each } \\
\text { space }\end{array}$ \\
\hline & $r s_{8}$ & $\begin{array}{l}\text { Change chiller to GREEN MARK } \\
\text { (Singapore benchmarking scheme } \\
\text { for buildings) gold certified } \\
\text { (Building and Construction } \\
\text { Authority 2016) }\end{array}$ & $\begin{array}{l}\text { Original COP: } 4.9 \\
\text { New COP: } 5.6\end{array}$ \\
\hline & $r s_{9}$ & $\begin{array}{l}\text { Apply High Chilled water supply } \\
\text { temperature }\end{array}$ & $\begin{array}{l}\text { Supply chilled water temperature at } 9{ }^{\circ} \mathrm{C} \text { (Original chilled } \\
\text { water temperature: } 6.7^{\circ} \mathrm{C} \text { ) }\end{array}$ \\
\hline & $r s_{10}$ & $\begin{array}{l}\text { Air to air heat ex-changer for } \\
\text { fresh air }\end{array}$ & $\begin{array}{l}\text { Sensible effectiveness: } 0.5 \\
\text { Latent effectiveness: } 0.35 \\
\text { Type: Plate }\end{array}$ \\
\hline
\end{tabular}

low e window based on the average market glazing property. $r s_{2}$ optimize the window performance by adding the solar control film to the exterior. In this study, the proposed solar control film will bring down the U-value of the existing windows from $6.3 \mathrm{~W} / \mathrm{m}^{2} \mathrm{~K}$ to $3.5 \mathrm{~W} / \mathrm{m}^{2} \mathrm{~K}$. $r s_{3}$ and $r s_{4}$ consider the insulation options of the building façade. Although there are different insulation types and layers in the market, the building physics follow similar principle and thus the impact on energy saving is not expected to have much difference. Hence in this study, the material was defined from open studio material library with the property described in Table 2. In the application of $r s_{5}$, this solar radiation is balanced by sensible (convection) and latent (evaporative) heat flux from cool roof. However, there is a limitation with the use of the Energy Plus simulation software. It could not take into account the impact of the cool roof on the ambient air temperature, which will in turn have an impact on the indoor solar gain.

$r s_{6}-r s_{10}$ are active solutions to be applied to the building systems. A previous study has shown a high infiltration rate with the building studied (Yang et al. 2016a), therefore, $r s_{7}$ aims to address the infiltration problem by reducing it to half. While it may be achieved through different implementations in the real situation, such as human behavior, regulation or vestibules installation, it is out of the scope of the discussion point of this study.

In $r s_{9}$, high chilled water supply temperature of $9{ }^{\circ} \mathrm{C}$ is applied. This is because in the current building chiller plant, the chilled water is designed to be about $6.7^{\circ} \mathrm{C}$. However, this might be inefficient when the load is well below the maximum load. After raised the chilled water temperature to $9{ }^{\circ} \mathrm{C}$, in this case, even when full load occurs, the typical over sizing of airside equipment 
would typically allow this increase of chilled water temperature. The energy-saving potential by applying high chilled water supply temperature may come from the reduced flow rate for the same capacity, which may lead to less cooling energy but also smaller pipes, pumps and insulation materials. However, during the simulation of this process in this study, the cooling coils may not accurately reflect the actual psychrometric processes and is considered as a limitation of this study.

Air-to-air heat exchanger systems have been in the market for decades. The ability for energy saving has been well demonstrated and documented (Deziani et al. 2017). In $r s_{10}$, the air-to-air heat exchanger systems, using cooling capacity recovered from exhaust air to temper the hot and humid outdoor air coming into the building is applied to help reduce the load and also the size of the air conditioning equipment to maintain the same set point within the spaces. The sensible effectiveness and latent effectiveness defined in this study are according to ARI Standard (ARI 2013) and ASHRAE standard (ASHRAE 2013) and the local weather situation. Therefore, a sensible effectiveness of 0.5 and a latent effectiveness of 0.35 are applied.

\subsection{Utilizability of combined scenarios}

Despite the urgent need for retrofitting as discussed in the first section and different technologies being developed, little research is currently being done for looking at the overlapping or synergistic performance of applying different technologies to a building. Most often, retrofit options are selected and driven by commercial or operational necessity: reducing energy demand, or reducing operational costs. Based on these factors, utilizability can be taken as a good index to evaluate and select the combination of retrofitting scenarios. It firstly gives the idea of the technology overlapping to avoid the wasted effort of a particular technology while achieving the energy saving amount and potential.
After the concept of utilizability is well defined, 44 combination cases as stated in Table 3, column 2, are explored that include all possible combinations between any 2 out of the selected 10 retrofitting scenarios. While there would be more possible cases by combining any 3 or even more retrofitting scnearios, the 44 cases as a case study would be able to demonstrate the application of the utilizability concept.

While the concept of utilizability can be applied to the combinations of more than 2 scenarios, the objective of this study is to explore the application of this developed expression for utilizability in the field of selecting the retrofitting, and therefore, the study limit the cases study to the exhaustive combinations among any two of the 10 retrofitting scneario. The principle can be extended to other retrofitting solutions and other combination possibilities.

In practice, utilizability would not be the only criterion to choose retrofitting solutions as different solutions have different levels of feasibility, cost, and intrusion, etc. The application of utilizability can be taken as the last few step when shortlisted retrofitting scenarios are selected based on other requirements and thus limited combinations would be tested.

The simulations are done through Energy Plus (U.S. Department of Energy 2011). Outdoor climate data including average outdoor temperature, relative humidity ratio, radiation, wind speed and direction, etc. are downloaded from the National University of Singapore (NUS) weather station located at the Department of Geography of NUS. Although there is Singapore weather files in the Energy Plus weather files library, the real weather data from NUS weather station are used as input into the weather file to have a more realistic input file.

Many studies have identified simulation as a good tool for building studies (Yang, Becerik-Gerber 2015; Ann 2002), such as its capability to evaluate the system performances when field experiments are infeasible and

Table 3. Combination cases

\begin{tabular}{cccccccc}
\hline Cases & $\begin{array}{c}\text { Combined } \\
\text { Scenarios }\end{array}$ & Cases & $\begin{array}{c}\text { Combined } \\
\text { Scenarios }\end{array}$ & Cases & $\begin{array}{c}\text { Combined } \\
\text { Scenarios }\end{array}$ & Cases & $\begin{array}{c}\text { Combined } \\
\text { Scenarios }\end{array}$ \\
\hline 1 & $r s_{1}+r s_{2}$ & 12 & $r s_{2}+r s_{5}$ & 23 & $r s_{3}+r s_{9}$ & 34 & $r s_{5}+r s_{9}$ \\
2 & $r s_{1}+r s_{3}$ & 13 & $r s_{2}+r s_{6}$ & 24 & $r s_{3}+r s_{10}$ & 35 & $r s_{5}+r s_{10}$ \\
3 & $r s_{1}+r s_{4}$ & 14 & $r s_{2}+r s_{7}$ & 25 & $r s_{4}+r s_{5}$ & 36 & $r s_{6}+r s_{7}$ \\
4 & $r s_{1}+r s_{5}$ & 15 & $r s_{2}+r s_{8}$ & 26 & $r s_{4}+r s_{6}$ & 37 & $r s_{6}+r s_{8}$ \\
5 & $r s_{1}+r s_{6}$ & 16 & $r s_{2}+r s_{9}$ & 27 & $r s_{4}+r s_{7}$ & 38 & $r s_{6}+r s_{9}$ \\
6 & $r s_{1}+r s_{7}$ & 17 & $r s_{2}+r s_{10}$ & 28 & $r s_{4}+r s_{8}$ & 39 & $r s_{7}+r s_{8}$ \\
7 & $r s_{1}+r s_{8}$ & 18 & $r s_{3}+r s_{4}$ & 29 & $r s_{4}+r s_{9}$ & 40 & $r s_{7}+r s_{9}$ \\
8 & $r s_{1}+r s_{9}$ & 19 & $r s_{3}+r s_{5}$ & 30 & $r s_{4}+r s_{10}$ & 41 & $r s_{7}+r s_{10}$ \\
9 & $r s_{1}+r s_{10}$ & 20 & $r s_{3}+r s_{6}$ & 31 & $r s_{5}+r s_{6}$ & 42 & $r s_{8}+r s_{9}$ \\
10 & $r s_{2}+r s_{3}$ & 21 & $r s_{3}+r s_{7}$ & 32 & $r s_{5}+r s_{7}$ & 43 & $r s_{8}+r s_{10}$ \\
11 & $r s_{2}+r s_{4}$ & 22 & $r s_{3}+r s_{8}$ & 33 & $r s_{5}+r s_{8}$ & 44 & $r s_{9}+r s_{10}$ \\
\hline
\end{tabular}


the investigation of various retrofitting solutions before being implemented. However, the reliability issue of using building energy models for assessing these solutions, especially the cross estimation between different solutions, has been well noticed in previous study (Li et al. 2015). While all the retrofitting solution are simulated based on the calibrated base case, there is lack of possible and available data to calibrate the model after applied each solutions.

This is taken as a limitation for simulation based studies.

The calibration was carried out using data collected from the year of 2013. The model was calibrated with identification model, which is described in detail in Yang et al. (2016d) referring to the metered data from BTU meter of this building and electricity meter of the buildings. With the calibrated model, the base case shows a coefficient of variation root mean square error of $8 \%$.

\section{Results and discussion}

\subsection{Utlizability results for the combined retrofitting solutions}

The results of the 44 cases including both savings amount and utilizability are shown in Figure 4.

The results provide an overview on the selection of retrofitting scenarios. Basically, the higher utilizability with higher savings amount would be preferred. It is interesting to observe that there are three very low value of utilizability: 0.57 for case 37 (Active Chilled Beam with DOAS system combined with replacement chiller with GM gold certified); 0.615 for case 1 (Replace Normal 6 $\mathrm{mm}$ clear glass to double glazed low E glass combined with adding solar control film); 0.65 for case 38 (Active Chilled Beam with DOAS system combined with applying high chilled water supply temperature). This means that the two technologies or solutions are working on the same building physics and cover a large part of the same energy saving areas, which lead to an inefficiency of utilization of each technology. This situation is not only peculiar for these three cases, but also for other combinations which may not even be included in the limited 44 cases. Further in detail, as shown in Figure 5, the marked areas with green have some very interesting points. It includes different combinations of scenarios but with similar utilizability but huge differences on energy savings. So the next step would be to investigate the sensitivity analysis for a few parameters of these scenarios.

\subsection{Utilizability sensitivity analysis}

Among the green areas, cases 2, 3, 6, 7 and 8 are selected for further utilizability sensitivity analysis, as all of them involve retrofitting scenario 1 . It would be interesting to see the trend of the impact of parameters from $r s_{1}$ (U-value and heat gain coefficient) on the different utilizability value. Specifically, the combinations can be stated as:

- Combination 1: Replace Normal $6 \mathrm{~mm}$ clear glass to double glazed low E glass + Reduce infiltration rate by half;

- Combination 2: Replace Normal $6 \mathrm{~mm}$ clear glass to double glazed low E glass + Change chiller to GM gold certified;

- Combination 3: Replace Normal 6 mm clear glass to double glazed low E glass + Apply High Chilled water temperature $\left(9^{\circ} \mathrm{C}\right)$;

- Combination 4: Replace Normal 6 mm clear glass to double glazed low E glass + Add roof insulation;

- Combination 5. Replace Normal $6 \mathrm{~mm}$ clear glass to double glazed low E glass + Add high performance insulation layer to external wall.

In combination cases 1-4, 2 parameters are considered separately: $U$ factor of the window; the solar heat gain coefficient of the window; in combination case 5, one additional parameter is considered: insulation layer thickness.

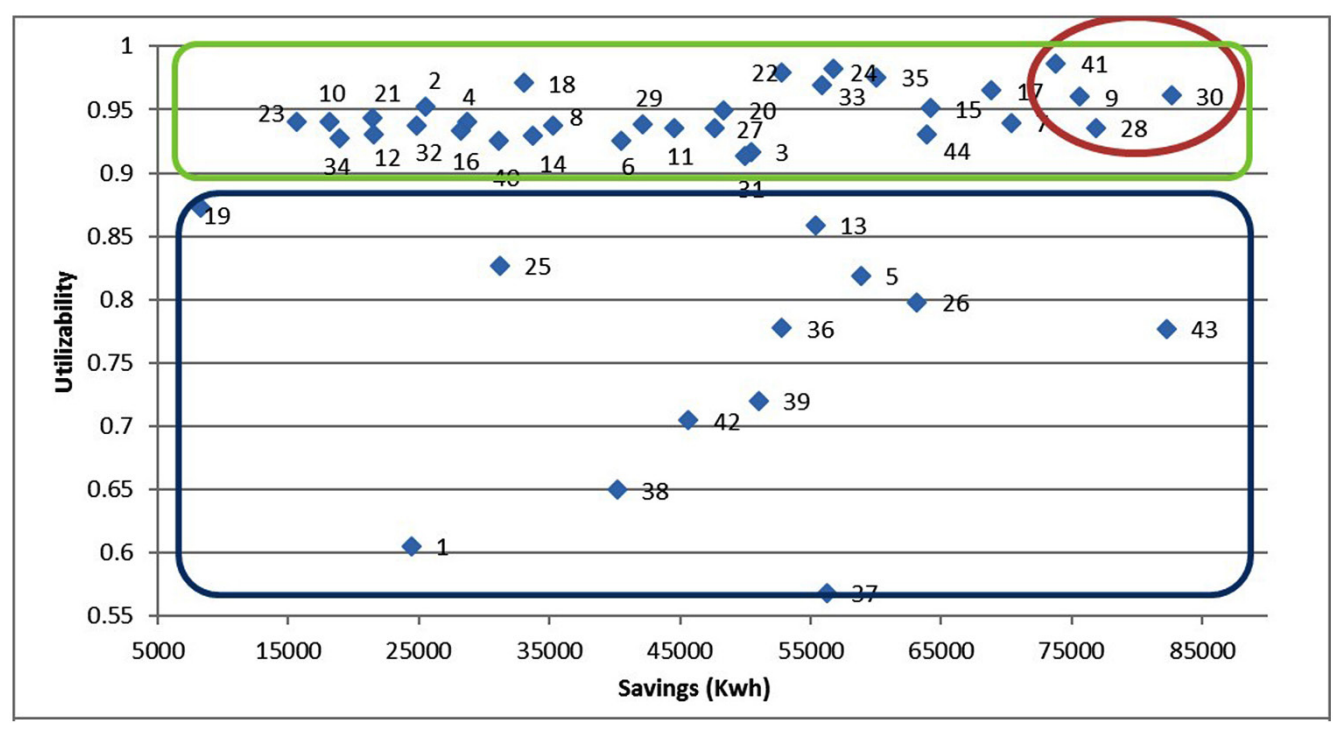

Fig. 4. Utilizability versus energy savings of the 44 cases 
In each sensitivity analysis, each parameter is randomly changed to 100 parametric values within the range of $+/-20 \%$ of the original value. It is well known that the more the number of samples is, the better the samples can represent probability function and real trend. However, too large a number of samples would require more computational time and resources. Here the number of parametric values (100) was chosen so that uncertainty quantification accuracy could be achieved with a reasonable computational time. The details of input variation are shown in Figure 5. EnergyPlus model of the building studied without any retrofitting solutions is used as the baseline model for comparison. For calculation of utilizability value of each combination cases 1-5, 1500 EnergyPlus IDF files are generated.

Firstly, it is interesting to see the utilizability and energy saving amount for each combination case with the change of each input parameter. Figure 6 represents two graphs for each combination case, as "utilizability vs changing parameter"; "energy saving amount vs changing parameter".

Through these figures, some interesting points can be observed. Firstly, in most cases, the changing trend of utilizability and energy saving amount has a very clear linear relationship, except the cases $6 c, 6 p, 6 r$ and $6 s$. When applying the replacement of normal $6 \mathrm{~mm}$ clear glass to double glazed low $\mathrm{E}$ glass together with adding roof insulation, or together with adding high performance insulation layer to external wall, it is observed that the thermodynamics will influence the utilizability of the two solutions in a relatively polynomial trend. Secondly, with the increase of $U$ value, the changing trend of utilizability is also different; e.g., it increases in combination case 1 while the value of utilizability will decrease in combination case 2 .

Finally, the graph between energy conservation and utilizability for all cases are plotted in Figure 7. As discussed previously, the good solutions are those where increase of the utilizability causes an increase of the energy gains, which is the win-win situation. According to Figure 7, while in some cases the utilizability decreases with the increase of energy saving, the solutions of "increase $\mathrm{U}$ value of SHGC in combination case 5 and combination case 3" are encouraging.

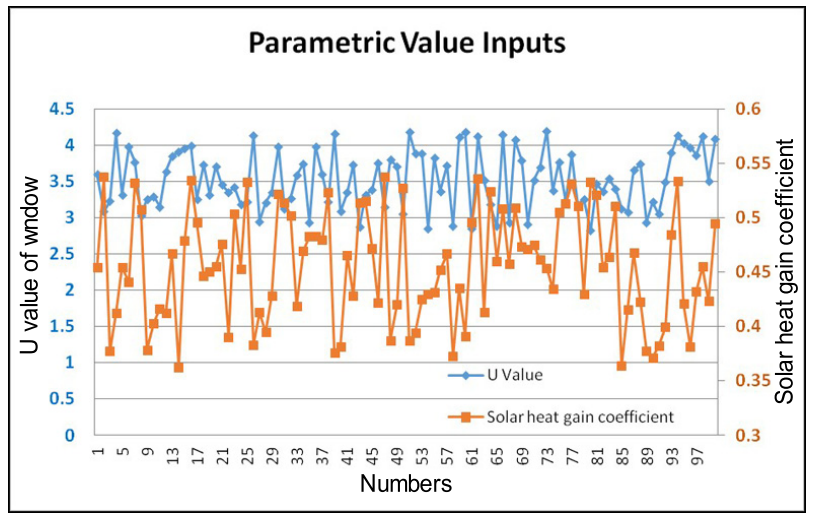

Fig. 5. Parametric value inputs for the sensitivity analysis

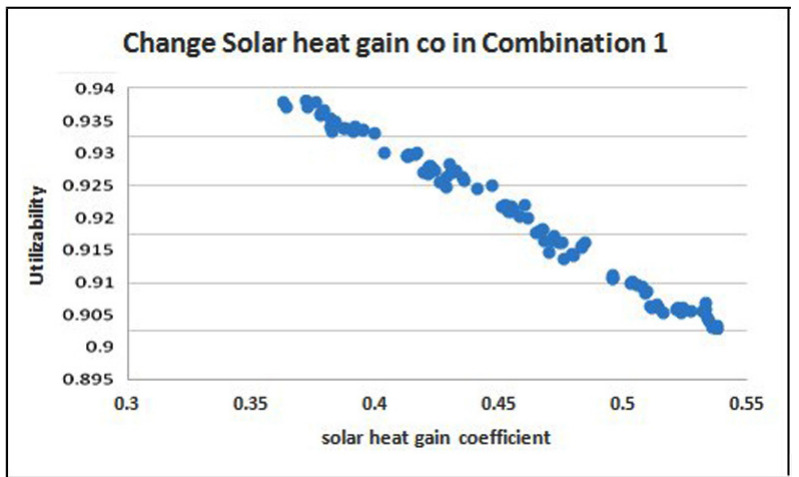

$6 a$

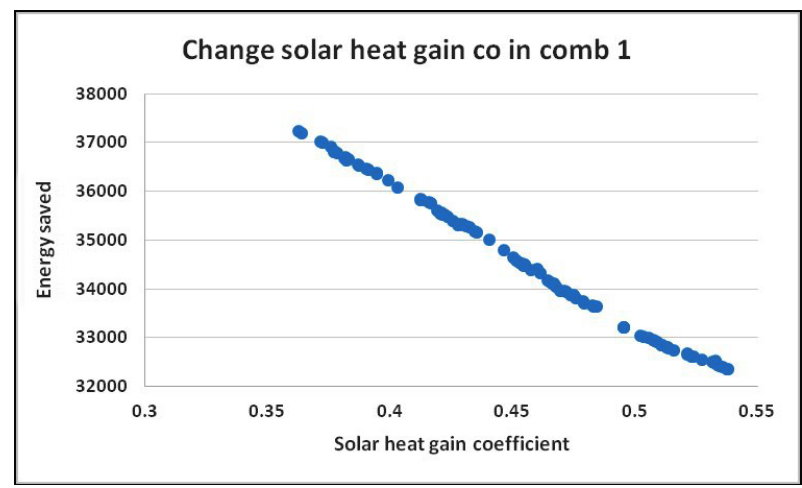

$6 \mathrm{~b}$

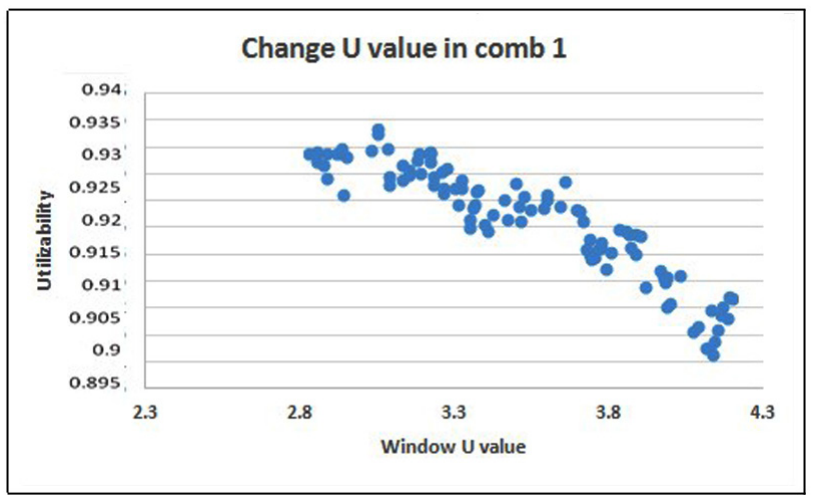

$6 c$

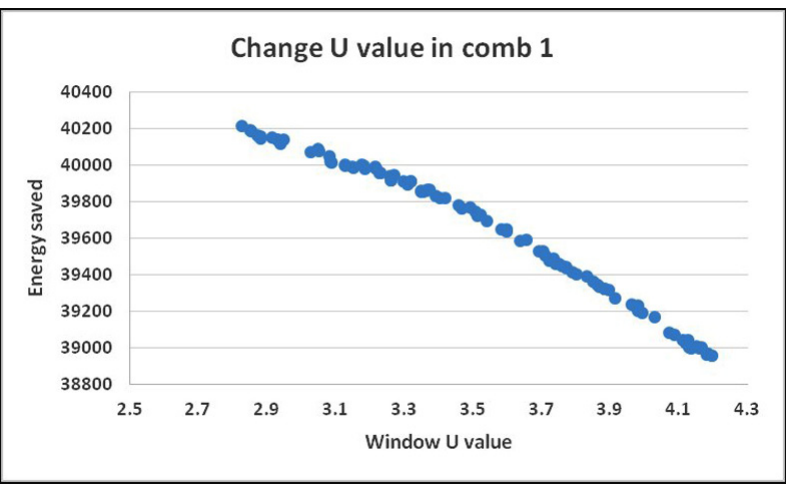

$6 d$

Fig. 6. Change of utilizability and energy saving with varying parameter $(a-d)$ 


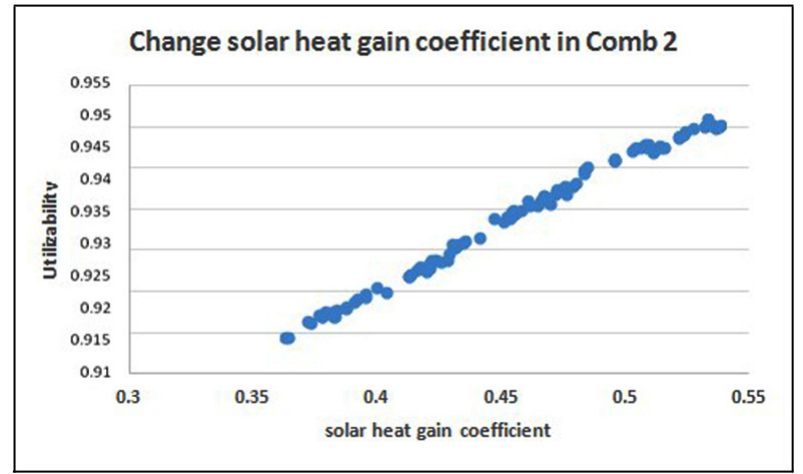

$6 \mathrm{e}$

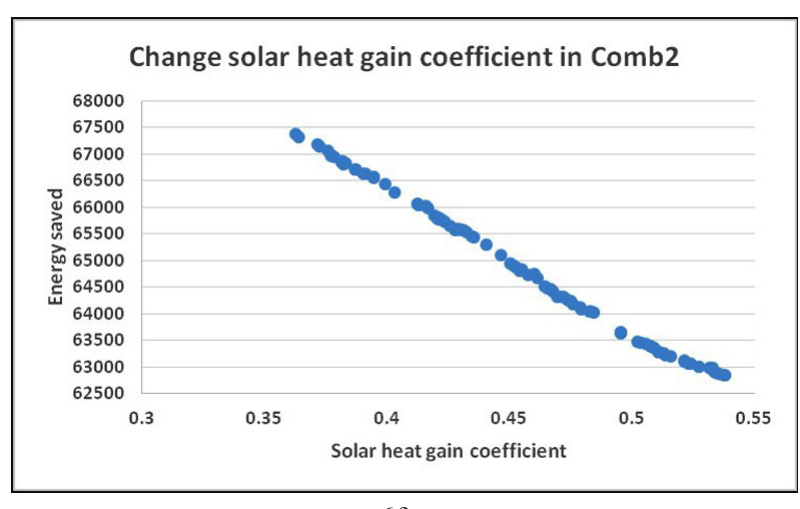

6f

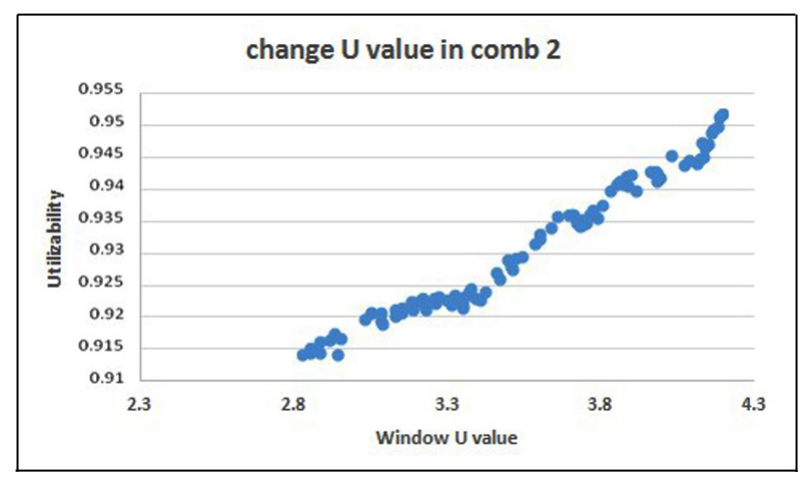

$6 g$

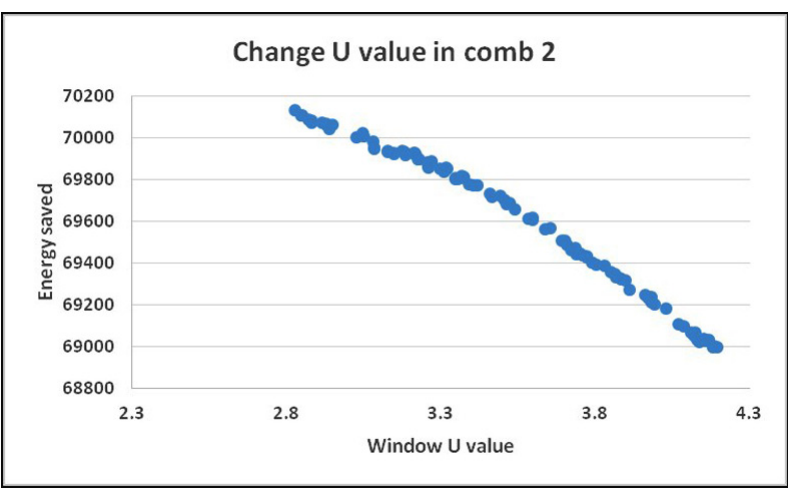

$6 \mathrm{~h}$

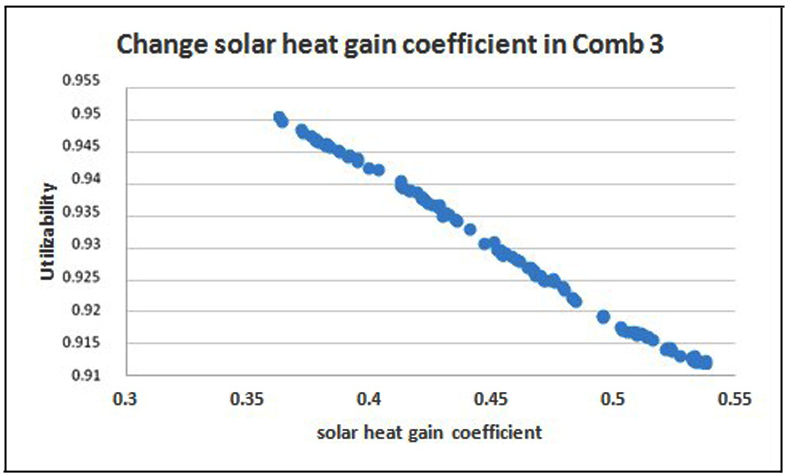

$6 \mathrm{i}$

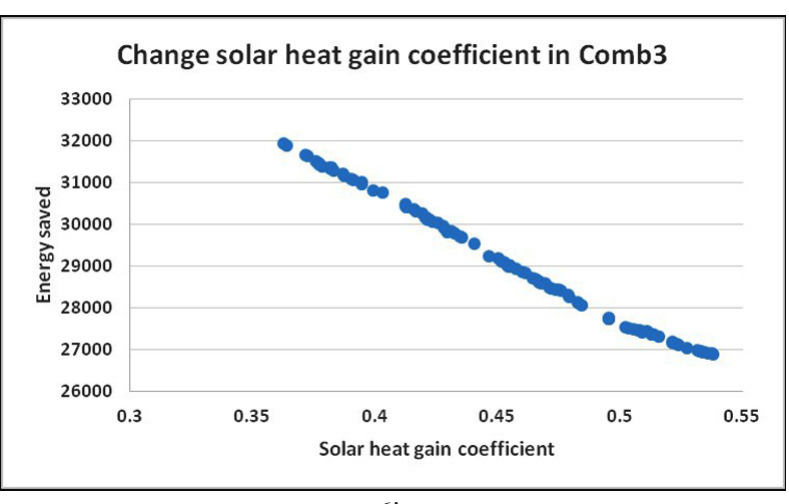

$6 \mathrm{j}$
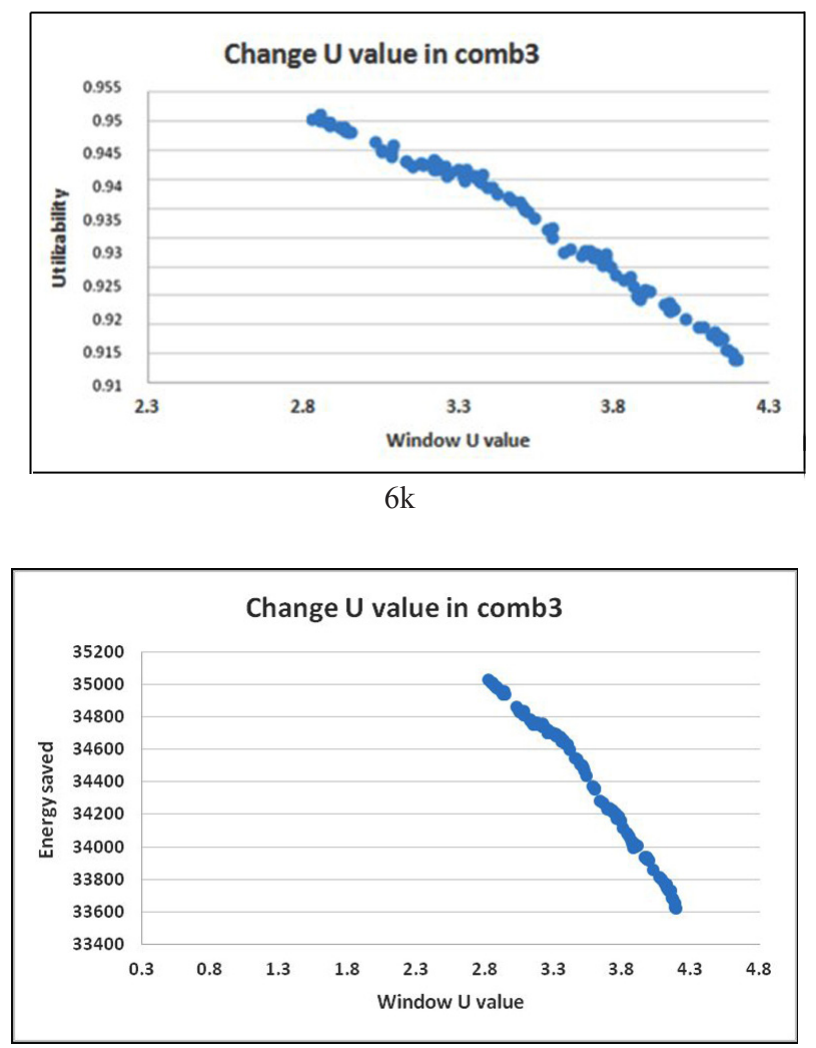

61

Fig. 6. Change of utilizability and energy saving with varying parameter (e-1) 


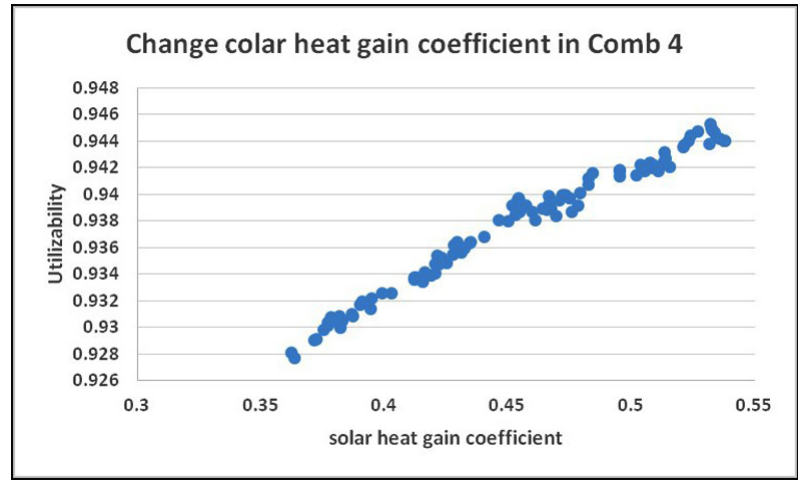

$6 \mathrm{~m}$

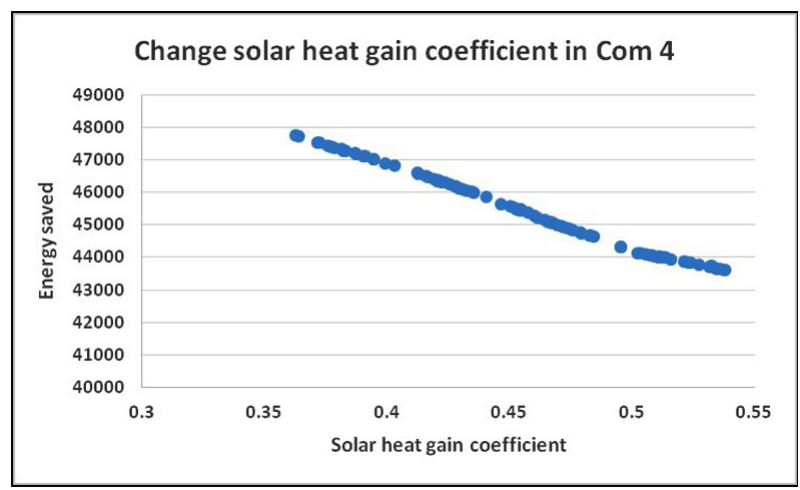

$6 n$

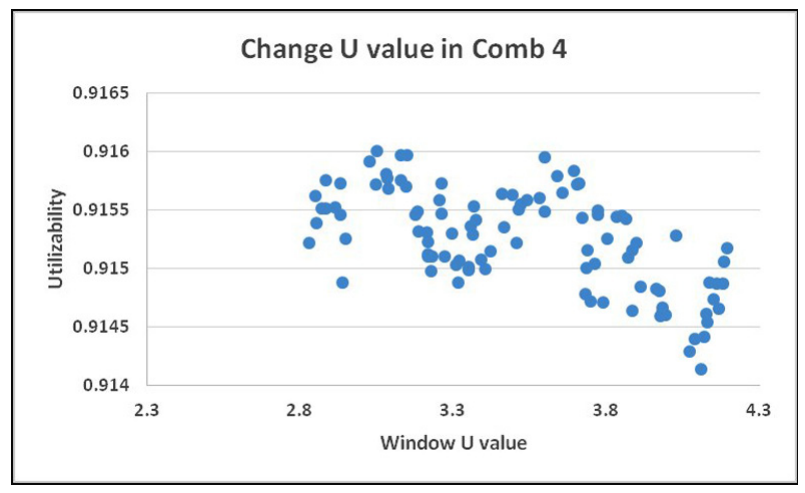

$6 p$

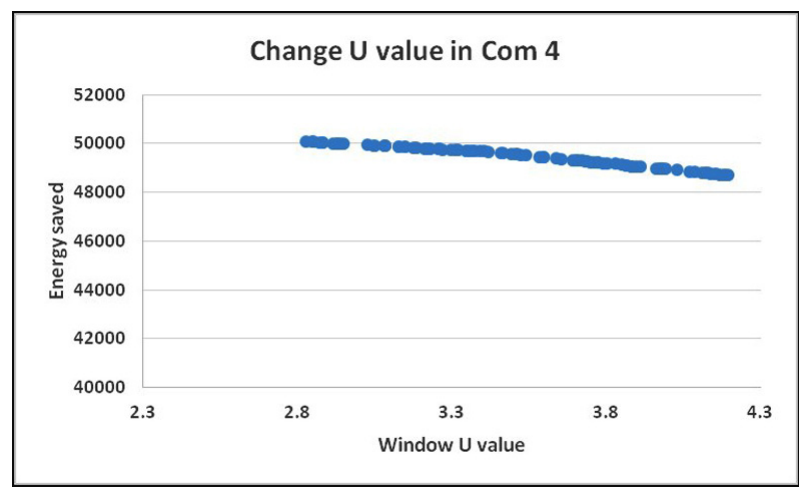

$6 q$

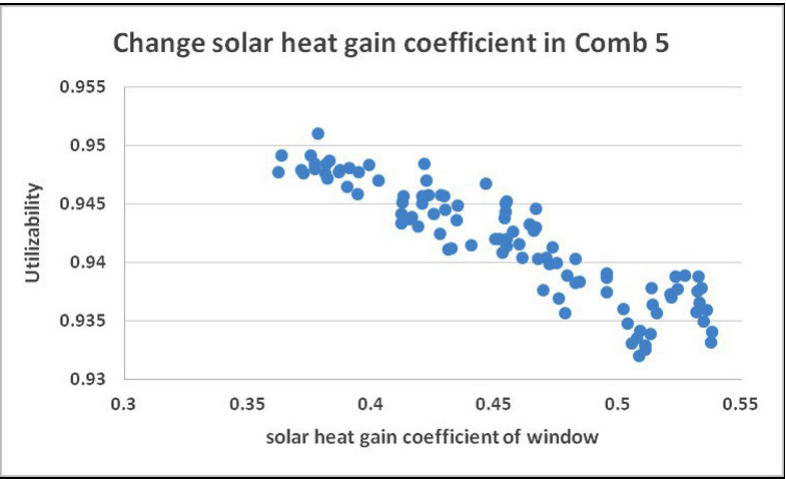

6r

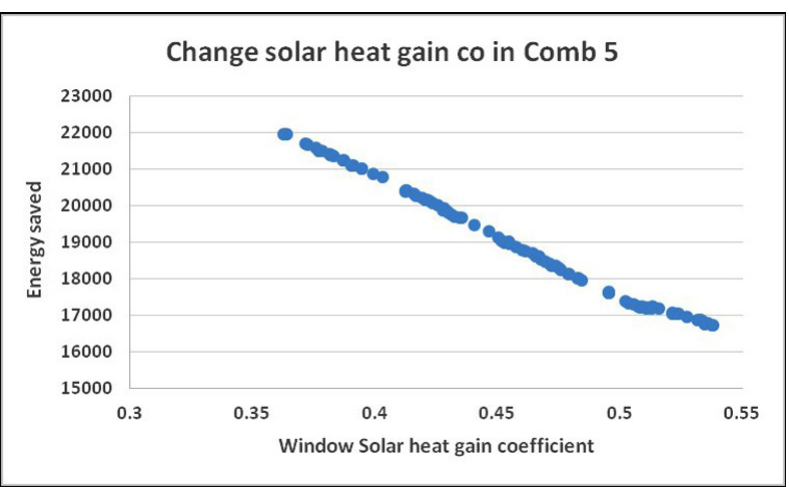

$6 s$

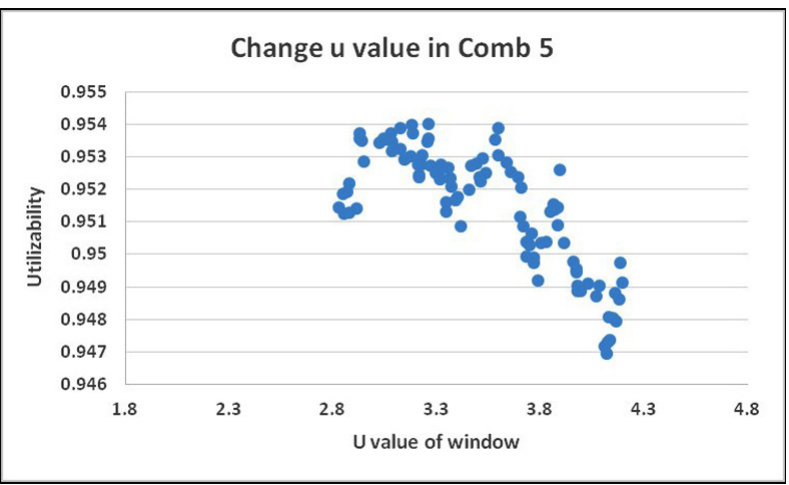

6ss

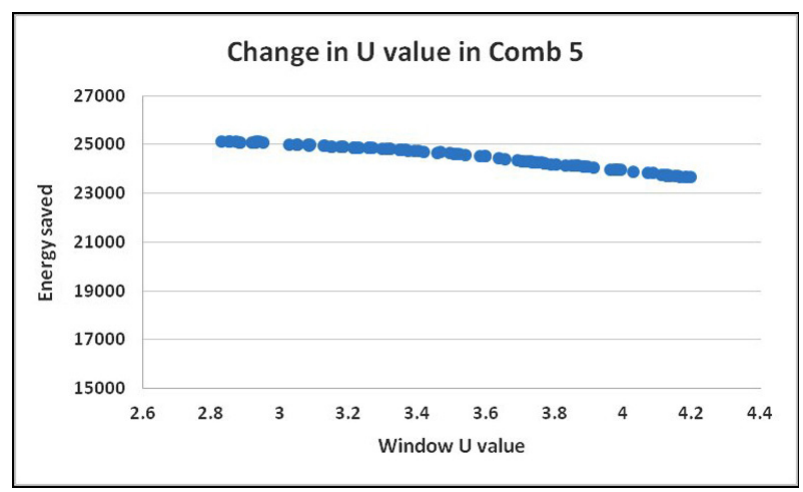

$6 \mathrm{t}$

Fig. 6. Change of utilizability and energy saving with varying parameter $(m-t)$ 


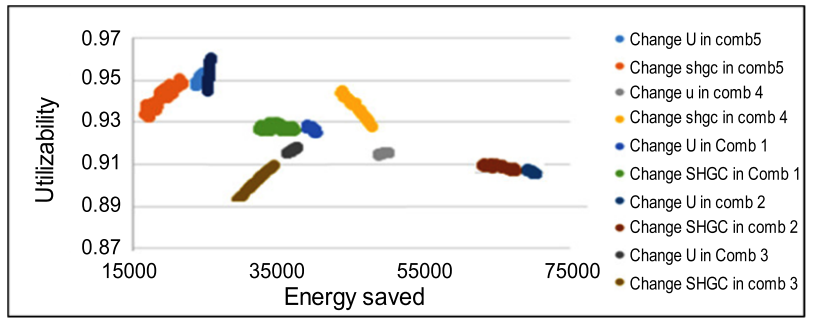

Fig. 7. Energy conservation vs utilizability for all cases

While the above cases just demonstrate a methodology to select the variable and combination case when more than 1 retrofitting solution is required to apply to a building, different parameters can be explored with the same methodology. For example, in combination case 5, wall insulation thickness could be investigated with the input samples shown in Figure 8; the results shown in Figure 9 demonstrated a win-win situation as well.

\section{Conclusions}

This study has developed an expression for utilizability in the retrofitting context of buildings, which simplifies the analysis and selection procedures in the field of applying multiple building retrofitting scenarios. The results from this case study have demonstrated the utilizability methodology and sensitivity analysis with random parameters and their application in building retrofitting solution combination and selection. This greatly facilitates the understanding of selecting different new technologies/solutions in the building systems. For the utilizability analysis, ten retrofitting solutions with 44 different combination cases are investigated. A large variation of utilizability from 0.57 to 0.98 was observed. While most of the cases fell within a small range of utilizability with a large energy savings amount difference, sensitivity analysis is deployed for a further investigation. 2200 EnergyPlus simulations were conducted for a five storey campus building in National University of Singapore. Both utilizability and energy savings amount were taken as sensitivity analysis index and three parameters: window $U$ value, window solar heat gain coefficient and wall insulation thickness. This simulation based sensitivity analysis study confirms that utilizability, in particular, together with energy savings amount, has to be taken into account when

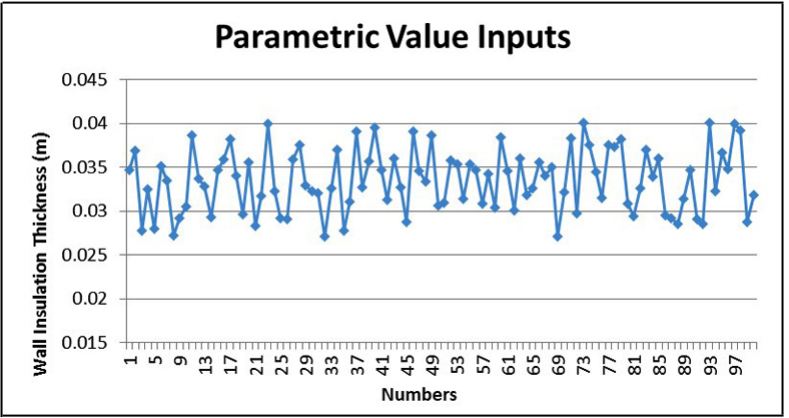

Fig. 8. Input samples of wall insulation thickness

applying more than one retrofitting solution. This study reveals that the best scenario is to have a better utilization of each individual retrofitting solution, which means a higher utilizability together with an increased amount of energy savings.

Due to the limitation of EnergyPlus capability on modelling unlimited parameters in all the 44 combination cases, only three parameters were investigated. However, the methodology stated in this study can be applied to any other parameters and combination cases for an economic and energy efficient optimisation of the building retrofitting sector.

\section{Funding}

The project is funded by National University of Singapore under CiBEST (BEE Hub).

\section{References}

Akbari, H.; Berdahl, P.; Levinson, R.; Wiel, S.; Miller, W.; Desjarlais, A. 2006. Cool-color roofing material. PIER building end-use energy efficiency program No. CEC-5002006-067. California Energy Commission.

Aktacir, M. A.; Büyükalaca, O.; Y1lmaz, T. 2010. A case study for influence of building thermal insulation on cooling load and air-conditioning system in the hot and humid regions, Applied Energy 87(2): 599-607. https://doi.org/10.1016/j.apenergy.2009.05.008

Ann, K. T. 2002. Energy savings in a commercial building with daylighting controls: empirical study and DOE-2 validation. Iowa State University, USA.

ARI. 2013. ARI Standard 1060-2013: Rating air-to-air energy recovery equipment. American Refrigeration Institute, Arlington, VA.
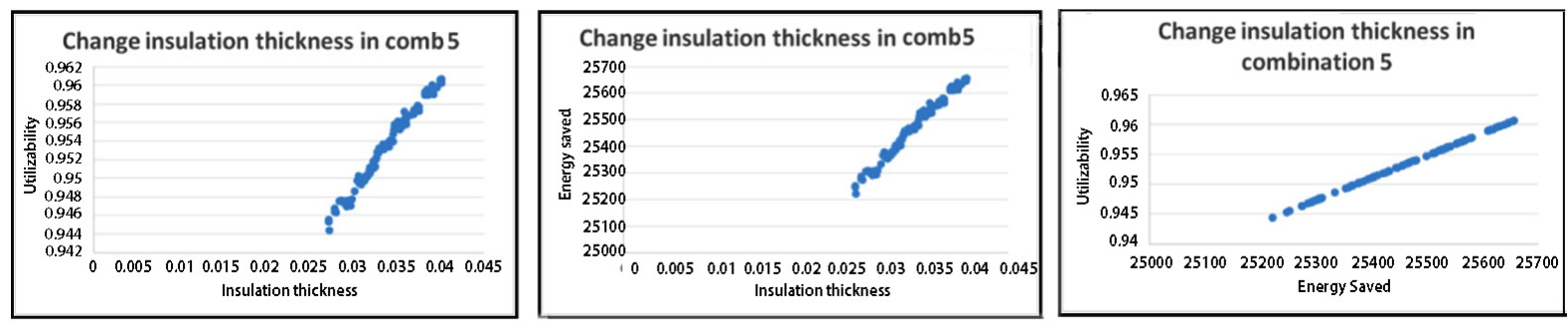

Fig. 9. Sensitivity analysis of wall insulation thickness in combination case 5 
ASHRAE. 2013. ASHRAE Standard 84-2013 Method of testing air-to-air heat/energy exchangers. American Society of Heating, Refrigerating and Air-Conditioning Engineers Inc., Atlanta.

Bianco, V.; Scarpa, F.; Tagliafico, L. A. 2017. Estimation of primary energy savings by using heat pumps for heating purposes in the residential sector, Applied Thermal Engineering 114: 938-947. https://doi.org/10.1016/j.applthermaleng.2016.12.058

BPIE. 2015. Addendum to the renovation strategies of selected EU countries. A Status Report on Compliance with Article 4 of the Energy Efficiency Directive. January 2015.

Building and Construction Authority. 2016. Green mark [online], [cited 10 Feb 2017]. Available from Internet:

https://www.bca.gov.sg/greenmark/green mark buildings.html

Chua, K. J.; Chou, S. K.; Yang, W. M.; Yan, J. 2013. Achieving better energy-efficient air conditioning - a review of technologies and strategies, Applied Energy 104: 87-104. https://doi.org/10.1016/j.apenergy.2012.10.037

de Santoli, L.; Mancini, F.; Rossetti, S.; Nastasi, B. 2016. Energy and system renovation plan for Galleria Borghese, Rome, Energy and Buildings 129: 549-562. https://doi.org/10.1016/j.enbuild.2016.08.030

Deziani, M.; Rahmani, Kh.; Roudaki, S. J. M.; Kordloo, M. 2017. Feasibility study for reduce water evaporative loss in a power plant cooling tower by using air to air heat exchanger with auxiliary Fan, Desalination 406: 119-124. https://doi.org/10.1016/j.desal.2015.12.007

Güçyeter, B.; Günaydın, H. M. 2012. Optimization of an envelope retrofit strategy for an existing office building, Energy and Buildings 55: 647-659. http://doi.org/10.1016/j.enbuild.2012.09.031

Jim, C. Y. 2014. Air-conditioning energy consumption due to green roofs with different building thermal insulation, Applied Energy 128: 49-59. https://doi.org/10.1016/j.apenergy.2014.04.055

Kuznik, F.; David, D.; Johannes, K.; Roux, J.-J. 2011. A review on phase change materials integrated in building walls, Renewable and Sustainable Energy Reviews 15(1): 379391. https://doi.org/10.1016/j.rser.2010.08.019

Li, N.; Yang, Z.; Becerik-Gerber, B.; Tang, C.; Chen, N. 2015. Why is the reliability of building simulation limited as a tool for evaluating energy conservation measures?, Applied Energy 159: 196-205. https://doi.org/10.1016/j.apenergy.2015.09.001

Nazi, W. I. W.; Wang, Y. D.; Roskilly, T. 2015. Methodologies to reduce cooling load using heat balance analysis: a case study in an office building in a tropical country, Energy Procedia 75: 1269-1274. https://doi.org/10.1016/j.egypro.2015.07.185

Nelson, I. C.; Culp, C. H.; Rimmer, J.; Tully, B. 2016 The effect of thermal load configuration on the performance of passive chilled beams, Building and Environment 96: 188197. https://doi.org/10.1016/j.buildenv.2015.11.017

Özkan, D. B.; Onan, C. 2011. Optimization of insulation thickness for different glazing areas in buildings for various climatic regions in Turkey, Applied Energy 88(4): 13311342. https://doi.org/10.1016/j.apenergy.2010.10.025

Pasupathy, A.; Velraj, R.; Seeniraj, R. V. 2008. Phase change material-based building architecture for thermal man- agement in residential and commercial establishments, Renewable and Sustainable Energy Reviews 12(1): 39-64. https://doi.org/10.1016/j.rser.2006.05.010

Pisello A. L.; Petrozzi, A.; Castaldo, V. L.; Cotana, F. 2015. On an innovative integrated technique for energy refurbishment of historical buildings: thermal-energy, economic and environmental analysis of a case study, Applied Energy 162: 1313-1322. https://doi.org/10.1016/j.apenergy.2015.05.061

Sabry, M.; Eames, P. C.; Singh, H.; Wu, Y. 2014. Smart windows: Thermal modelling and evaluation, Solar Energy 103: 200-209. https://doi.org/10.1016/j.solener.2014.02.016

Sekhar, S. C. 2007. A review of ventilation and air-conditioning technologies for energy-efficient healthy buildings in the tropics, ASHRAE Transactions 113, Part 1, 426-434.

Sozer, H. 2010. Improving energy efficiency through the design of the building envelope, Building and Environment 45(12): 2581-2593. https://doi.org/10.1016/j.buildenv.2010.05.004

Todorovic, M. S.; Ecim, O. 2010. Multidisciplinary engineering assessment to approach sustainable ZE-ECO-Settlement, in Passive and Low Energy Cooling - PALENC, 29 September - 1 October 2010, Rhodos, Greece.

U.S. Department of Energy. 2011. Building energy data book. Energy efficiency \& renewable energy [online], [cited 10 Jan 2017]. Available from Internet: http://buildingsdatabook.eren.doe.gov/docs\%5CDataBooks\%5C2011_ BEDB.pdf

Wong, N. H.; Li, S. 2007. A study of the effectiveness of passive climate control in naturally ventilated residential buildings in Singapore, Building and Environment 42: 1395-1405. https://doi.org/10.1016/j.buildenv.2005.11.032

Yang, J.; Pantazaras, A.; Lee, S. E.; Santamouris, M. 2016a. Retrofitting solutions for two different occupancy levels of educational buildings in tropics, International Journal of Sustainable Energy, 1-15 (in press). https://doi.org/10.1080/14786451.2016.1177052

Yang, J.; Santamouris, M.; Lee, S. E.; Deb, C. 2016d. Energy performance model development and occupancy number identification of institutional buildings, Energy and Buildings 123: 192-204. https://doi.org/10.1016/j.enbuild.2015.12.018

Yang, J.; Tham, K. W.; Lee, S. E.; Santamouris, M.; Sekhar, C.; Cheong, D. 2016c. Anthropogenic heat reduction through retrofitting strategies of campus buildings, Energy and Buildings (in press). https://doi.org/10.1016/j.enbuild.2016.11.051

Yang, Z.; Becerik-Gerber, B. 2015. A model calibration framework for simultaneous multi-level building energy simulation, Applied Energy 149: 415-431.

https://doi.org/10.1016/j.apenergy.2015.03.048

Yang, Z.; Becerik-Gerber, B. 2017. Assessing the impacts of real-time occupancy state transitions on building heating/ cooling loads, Energy and Buildings 135: 201-211. https://doi.org/10.1016/j.enbuild.2016.11.038

Yang, Z.; Ghahramani, A.; Becerik-Gerber, B. 2016b. Building occupancy diversity and HVAC (heating, ventilation, and air conditioning) system energy efficiency, Energy 109: 641-649. https://doi.org/10.1016/j.energy.2016.04.099 
Junjing YANG. PhD. Research Fellow at Department of Building, National University of Singapore. Her primary research interests include building energy efficiency, ventilation and IAQ, energy and indoor environment data analysis/analytics.

Adrian CHONG. PhD student in Building Performance and Diagnostics at Carnegie Mellon University. He is also a teaching assistant in the Department of Building at the National University of Singapore where he received his MSc in Building Science. His primary research interests include calibration of building energy models, uncertainty quantification and building data analytics.

Matthaios SANTAMOURIS. PhD. Professor of High Performance Architecture at UNSW, and Professor in the University of Athens, Greece. Visiting Professor: Cyprus Institute, Metropolitan University London, Tokyo Polytechnic University, Bolzano University, Brunnel University and National University of Singapore. Past President of the National Center of Renewable and Energy Savings of Greece. Editor in Chief of the Energy and Buildings Journal, Past Editor in Chief of the Advances Building Energy Research, Associate Editor of the Solar Energy Journal and Member of the Editorial Board of 14 Journals. Editor of the Series of Book on Buildings, published by Earthscan Science Publishers. Editor and author of 14 international books published by Earthscan, Springer, etc. Author of 270 scientific articles published in journals. Reviewer of research projects in 15 countries including USA, UK, France, Germany, Canada, Sweden, etc.

Dionysia KOLOKOTSA. PhD. She is Associate Professor at the School of Environmental Engineering of the Technical University of Crete, Greece. She is the Head of the Energy Management in the Built Environment Research Lab Her research interests include energy management for the built environment, energy efficiency and renewables. Moreover she has developed expertise in the field of urban energy dynamics, environmental and ecological impact at the metropolitan and regional scale with an emphasis on the urban heat island mitigation and adaptation strategies. She is the author of more than 100 papers published in high impact scientific journals and conference proceedings. She is the Editor-in-Chief of the Advances in Building Energy Research, Taylor and Francis as well as Editorial Board Member of Renewable Energy and Energy and Buildings Journal of Elsevier.

Siew Eang LEE. PhD, Associate Professor in the Department of Building at the National University of Singapore. He is the CoDirector of Building Energy Efficiency Hub. His primary research interests include Building Acoustics, Building Energy Efficiency and Environment Assessment Systems. He also serves on many Singapore national committees and programmes as technical member and advisor.

Kwok Wai THAM. PhD, Associate Professor in the Department of Building at the National University of Singapore. He is the Co-Director of Building Energy Efficiency Hub. He is an Academy Fellow of the International Academy for Indoor Air Sciences (IAIAS) and was the President of the International Society of Indoor Air Quality and Climate (ISIAQ). His research interests include Indoor Environment Quality and Indoor Environment Health.

Chandra SEKHAR. PhD, Professor in the Department of Building at the National University of Singapore. He is the Program Director of the MSc (Building Performance and Sustainability) program and a Co-Director of the Centre for Integrated Building Energy and Sustainability in the Tropics. His primary research interests include thermal comfort, ventilation and IAQ, energy efficient HVAC systems and energy and indoor environment data analysis/analytics. He is a Fellow and a Distinguished Lecturer of ASHRAE and is active in some of its Technical and Standardisation activities. He is also a Fellow of ISIAQ.

David K. W. CHEONG. PhD, Associate Professor in the Department of Building at the National University of Singapore. He is the Vice-Dean in the School of Design and Environment and a Co-Director of the Centre for Integrated Building Energy and Sustainability in the Tropics. His primary research interests include ventilation and IAQ, migration of pollutants between indoor and outdoor spaces, as well as energy analytics for indoor environment. He is a Fellow of ISIAQ (International Society of Indoor Air Quality and Climate). 